\title{
A Review of Ranibizumab Clinical Trial Data in Exudative Age-Related Macular Degeneration and How to Translate It into Daily Practice
}

\author{
Jordi Monés \\ Institut de la Màcula i de la Retina, Centro Médico Teknon, Barcelona, Spain
}

\section{Key Words}

Age-related macular degeneration - Ranibizumab •

MARINA $\cdot$ ANCHOR $\cdot$ EXCITE $\cdot$ SUSTAIN $\cdot$ PrONTO $\cdot$ PIER

\begin{abstract}
The results of randomized controlled clinical trials of ranibizumab for the treatment of age-related macular degeneration established a new standard of care with the prospect of improved vision in many patients. Subsequent trials have explored different strategies to increase response rates and reduce treatment frequency. This review analyzes the key clinical trial data for ranibizumab on the basis of which the author proposes a new treatment regimen with the aim of rationalizing treatment frequency without compromising improvements in vision - the FUSION regimen. This consists of an initiation phase followed by pro re nata (PRN) retreatment combined with fixed injections after a period of disease inactivity of 2-4 months (depending on the time elapsed since the last injection). A randomized clinical trial is recommended for comparing monthly, PRN and the FUSION regimens.

Copyright @ 2010 S. Karger AG, Basel
\end{abstract}

J.M. is scientific advisor for Novartis, Allergan, Ophthotech and Notalvision.

\section{KARGER}

Fax +41613061234 E-Mail karger@karger.ch www.karger.com
(C) 2010 S. Karger AG, Base

0030-3755/11/2252-0112\$38.00/0

Accessible online at:

www.karger.com/oph
The results from the MARINA and ANCHOR studies marked a significant change in treatment outcomes for age-related macular degeneration $[1,2]$. For the first time, patients' average visual acuity improved, and more than one third of the patients experienced an improvement of $>3$ Early Treatment Diabetic Retinopathy Study (ETDRS) lines (fig. 1) [1,2]; a true new standard of care for the treatment of this disabling disease was established.

Despite the ophthalmology community's joy at this new development, the inconvenience of monthly injections remained. The frequency of therapy raised concerns of potential ocular and systemic safety risks. In addition, secondary issues such as the logistical feasibility of the regimen, patients' compliance and the costs of the monthly treatment became increasingly apparent. Other treatment regimens were soon being investigated to try to obtain the same efficacy with fewer injections.

The first alternative strategy to monthly injections was tested in the PIER study [3] and consisted of an initiation phase followed by a fixed dose of intravitreal ranibizumab every 3 months. Retreatment was not dependent on predetermined criteria. The vision results were good compared with the control group: at 12 months, the mean visual acuity in ranibizumab-treated patients was 16 letters greater than that of the control group. However, unlike the results from the MARINA 

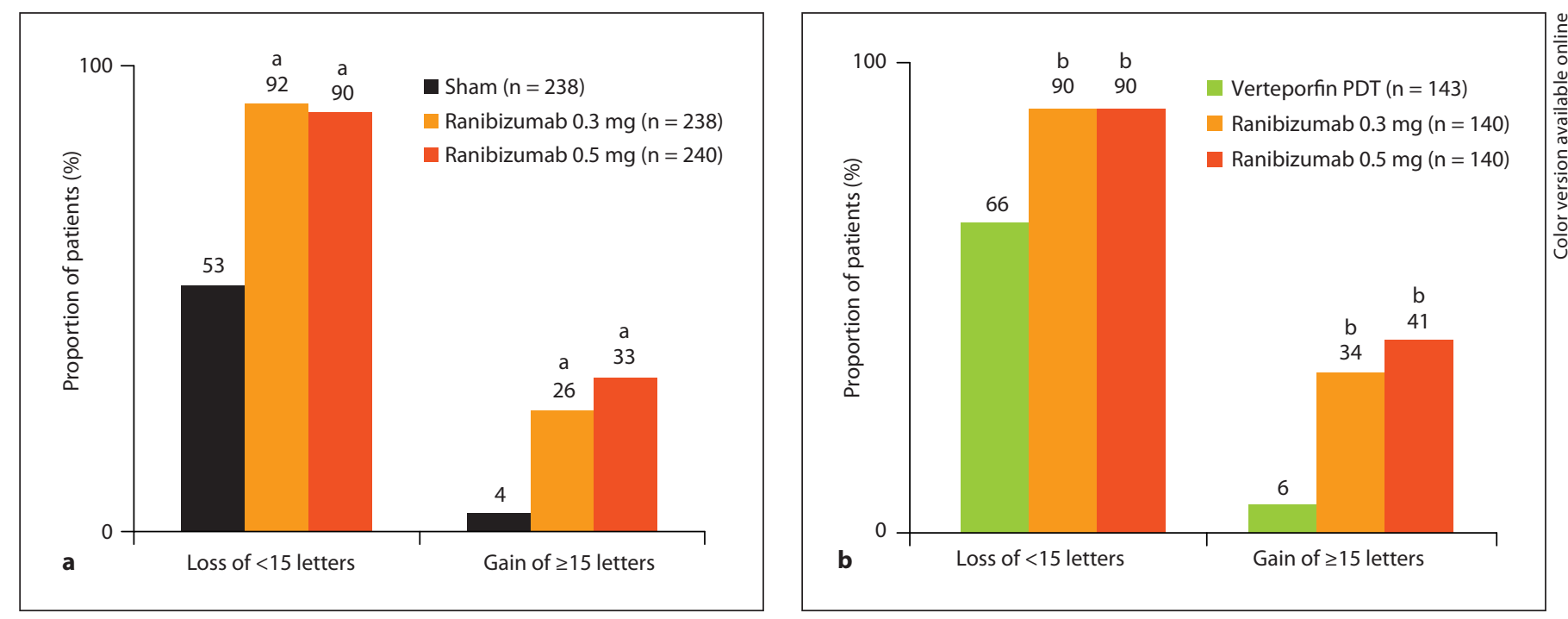

Fig. 1. Proportion of patients achieving vision gain and avoiding vision loss in the MARINA (a) and ANCHOR (b) studies: monthly injections over 24 months. ${ }^{\mathrm{a}} \mathrm{p}<0.001$ versus sham; ${ }^{\mathrm{b}} \mathrm{p}<0.0001$ versus verteporfin photodynamic therapy (PDT).

and ANCHOR studies, there was no overall vision improvement. It must be emphasized, however, that there was an initial improvement in the initiation phase, which was later lost in the period of quarterly maintenance injections.

In the SAILOR study, ranibizumab doses of 0.3 and $0.5 \mathrm{mg}$ were evaluated without a control group [4]. The treatment schedule consisted of an initiation phase followed by a maintenance phase of on-demand or pro re nata (PRN) retreatment based on vision and optical coherence tomography (OCT) criteria. The overall results of this study were similar to the PIER study in that there was no improvement versus baseline. However, subgroup analyses indicated that an alternative regimen could benefit some patients: $40 \%$ of patients in the PIER study had an initial improvement in visual acuity following the first 3 monthly injections that was maintained by quarterly fixed-dose injections, resulting in a gain of about 9 letters in 12 months (fig. 2; data on file: Novartis).

These results encouraged the search for further alternative strategies. In the EXCITE study, patients were given an injection each month for the first 3 months and were seen monthly thereafter for an OCT evaluation (this was not done in the PIER study) [5]. One group of patients was retreated monthly, whereas the other 2 groups were given 1 of the 2 doses of ranibizumab quarterly over 12 months [5]. The results confirmed that the

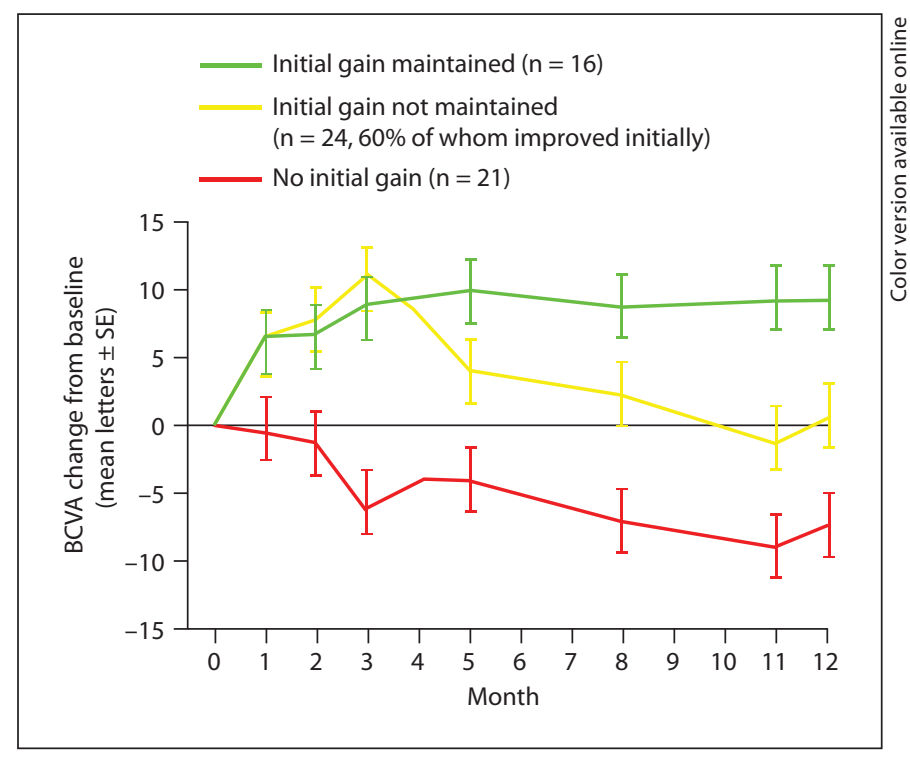

Fig. 2. Subgroup analysis in the PIER study [3]. The PIER study regimen maintained the initial improvement in $40 \%$ of patients $(\mathrm{n}=16) . \mathrm{BCVA}=$ Best-corrected visual acuity; $\mathrm{SE}=$ standard error.

monthly dosing regimen was more effective than the quarterly one. The average visual acuity of patients receiving the monthly treatment not only improved by 6 letters in the first 3 months, but continued to improve, reaching 8 letters by the 12 -month visit. Patients who re- 
Fig. 3. Change in average visual acuity in the EXCITE study: initiation phase + monthly injections versus fixed injections of ranibizumab $0.3 \mathrm{mg}$ or $0.5 \mathrm{mg}$ every 3 months [5]. BCVA = Best-corrected visual acuity; $\mathrm{SE}=$ standard error.

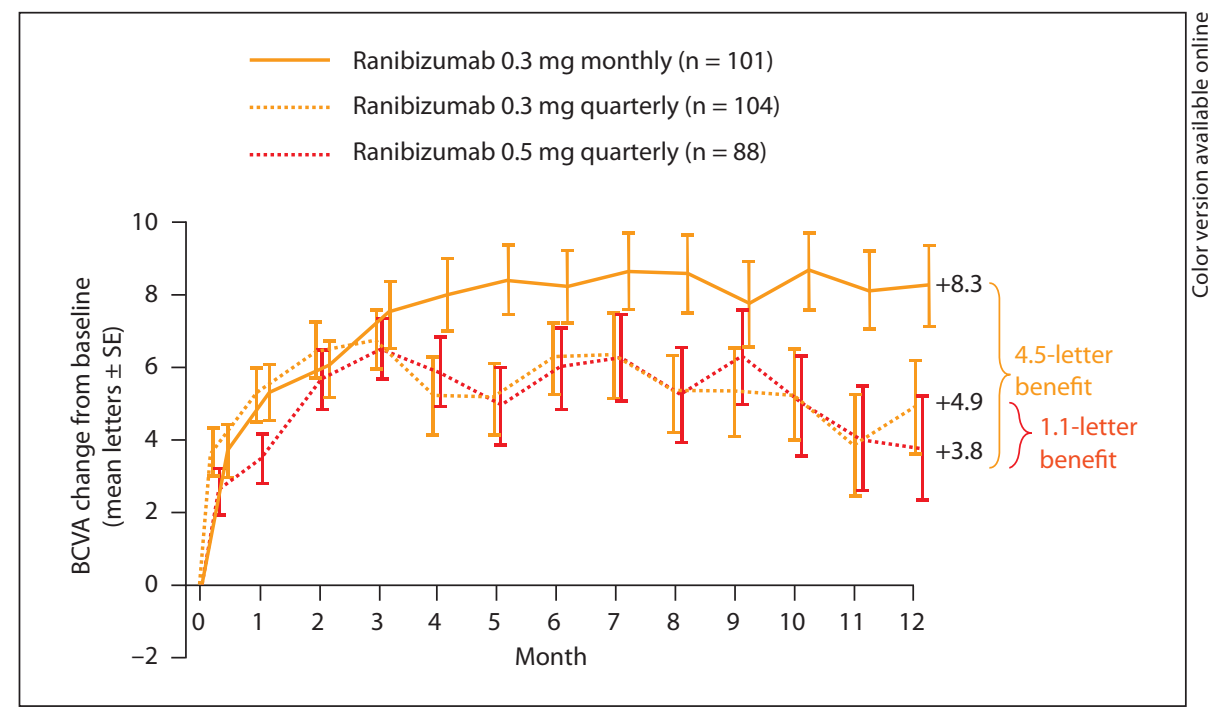

ceived quarterly treatment also experienced an improvement of 6 letters in the first 3 months but only managed an improvement of 4.5 letters by the end of 12 months (fig. 3) [5]. Similar to findings in the PIER study, $43 \%$ of quarterly regimen patients in the EXCITE study obtained a gain in visual acuity similar to that of the monthly regimen patients [6].

The PrONTO study examined a PRN regimen with monthly visits in 40 patients [7]. Following the initiation phase, retreatment was given monthly, depending on preestablished vision and OCT criteria. Eighty-two percent of patients experienced no loss of vision, and there was an average visual acuity gain of 9.3 letters after the first 3 months, which remained stable for the full 12 months. These results were similar to those obtained in the MARINA and ANCHOR studies, but instead of 13 injections, an average of only 5.9 injections was given during the PrONTO study over a period of 1 year $[1,2,7]$. However, this study did have major limitations: it was a small, openlabel, centralized study that lacked a control group and 2 patients dropped out. Therefore, although PrONTO yielded positive results, validation from larger-scale trials was required.

This requirement led to the design of a new multicenter clinical study called SUSTAIN, which investigated an individualized ranibizumab PRN regimen in 513 patients without a control group [8]. Following the initiation phase, retreatment was based on criteria similar to those in the PrONTO study: principally, a loss of $>5$ ETDRS letters or a $100-\mu \mathrm{m}$ increase in retinal thickness, as compared with the best values after the initiation phase. The visual acuity results were positive: with an average of 5.6 injections, there was an average improvement in visual acuity of 3.6 letters after 12 months. However, once again, the improvement of 5.8 letters made in the initiation phase was not maintained [8].

Therefore, apart from the limited PrONTO study, alternative ranibizumab regimens have not achieved the same levels of efficacy as the monthly injections studied in MARINA and ANCHOR (fig. 4; data on file: Novartis). Authors of studies on series of patients treated with PRN regimens have reported similar results and have yet to obtain the efficacy results of MARINA and ANCHOR [9, 10].

In an attempt to better understand the clinically critical difference between PRN regimens and the monthly dosing regimen, it is worthwhile to consider the differences in the dynamics of vision loss and its recovery after a relapse. This is well illustrated by an analysis carried out in the SUSTAIN study [11]. If the retreatment criterion was a loss of $>5$ letters, the average loss when patients were treated was 9.21 letters, signifying that, despite the monitoring, the loss was almost 2 lines of vision at the time of its detection. However, the average gain after the next injection following this loss was only 2.6 letters. This meant that, in the majority of cases, although treatment was given after recording the loss, this did little towards re-establishing previous levels of vision. This analysis also showed that the longer the period between the last injection and vision loss, the less the vision recovery following the subsequent injection (fig. 5) [11]. 
Fig. 4. Change in average visual acuity in the different arms of the main clinical trials with ranibizumab for exudative agerelated macular degeneration (data on file: Novartis). BCVA = Best-corrected visual acuity; PDT $=$ photodynamic therapy.

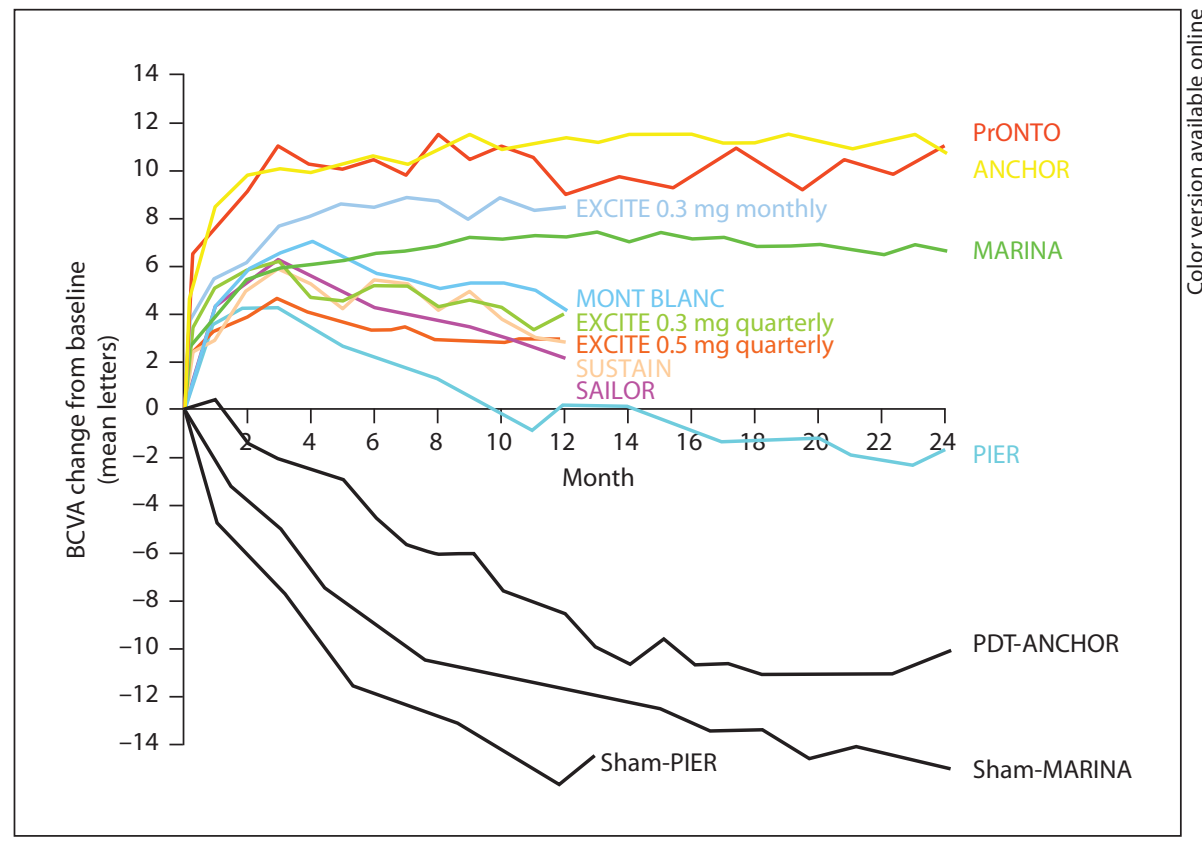

Fig. 5. Average vision loss in the SUSTAIN study at the time of detection and improvement following the next injection, with respect to the time elapsed from the last injection until the detection of loss [11]. BCVA = Best-corrected visual acuity.

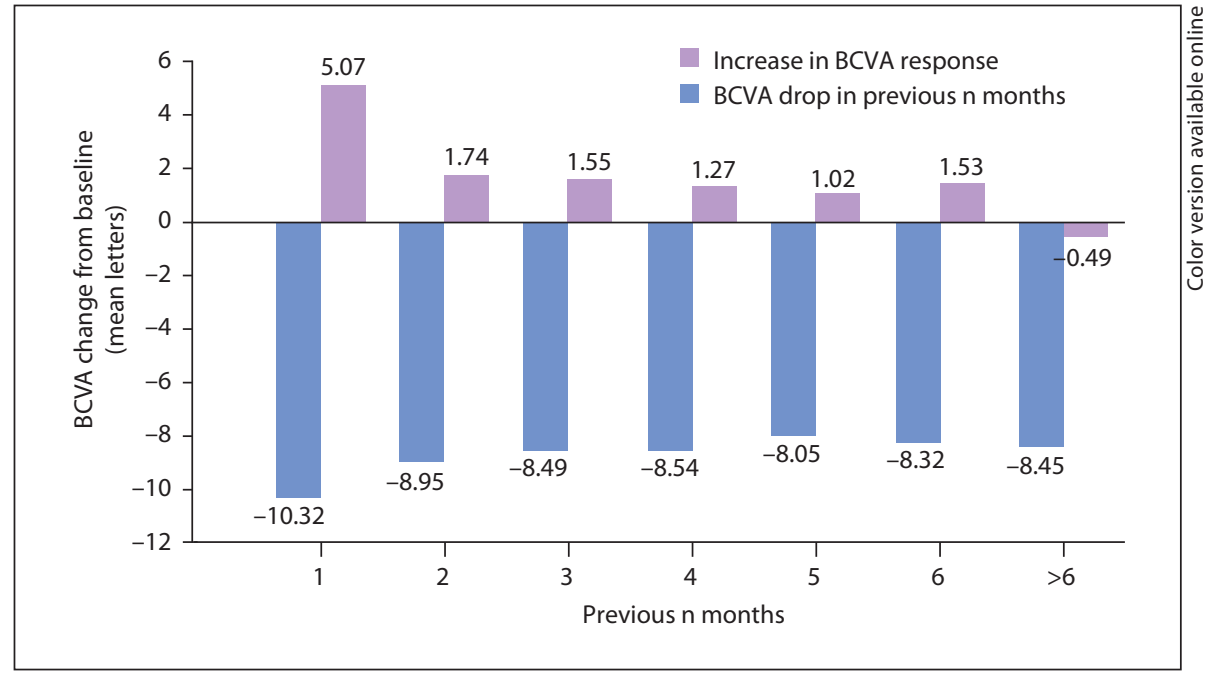

This analysis and the aforementioned studies show that PRN regimens, by definition, lag behind disease progression. Retreatment is only given once the lesion shows signs of activity and incremental vision loss has already occurred, which may not be recoverable - it is incredibly difficult to re-establish baseline levels and maintain previous improvement after a relapse. Thus, the disease has the initiative. The key to the success of monthly dosing might possibly lie in treating before further disease progression, i.e. treatment being administered even when the lesion is inactive. In this approach, the treatment has the advantage - not the disease. If this theory is correct, the ideal treatment would be one that anticipates and prevents disease progression without the need for fixed monthly injections.

In summary, the combined information from all the ranibizumab clinical trials indicates that: (1) 3 out of 4 patients retain their vision; (2) 1 out of 3 patients can significantly improve their vision; (3) more injections provide more sustained benefits, with monthly injec- 


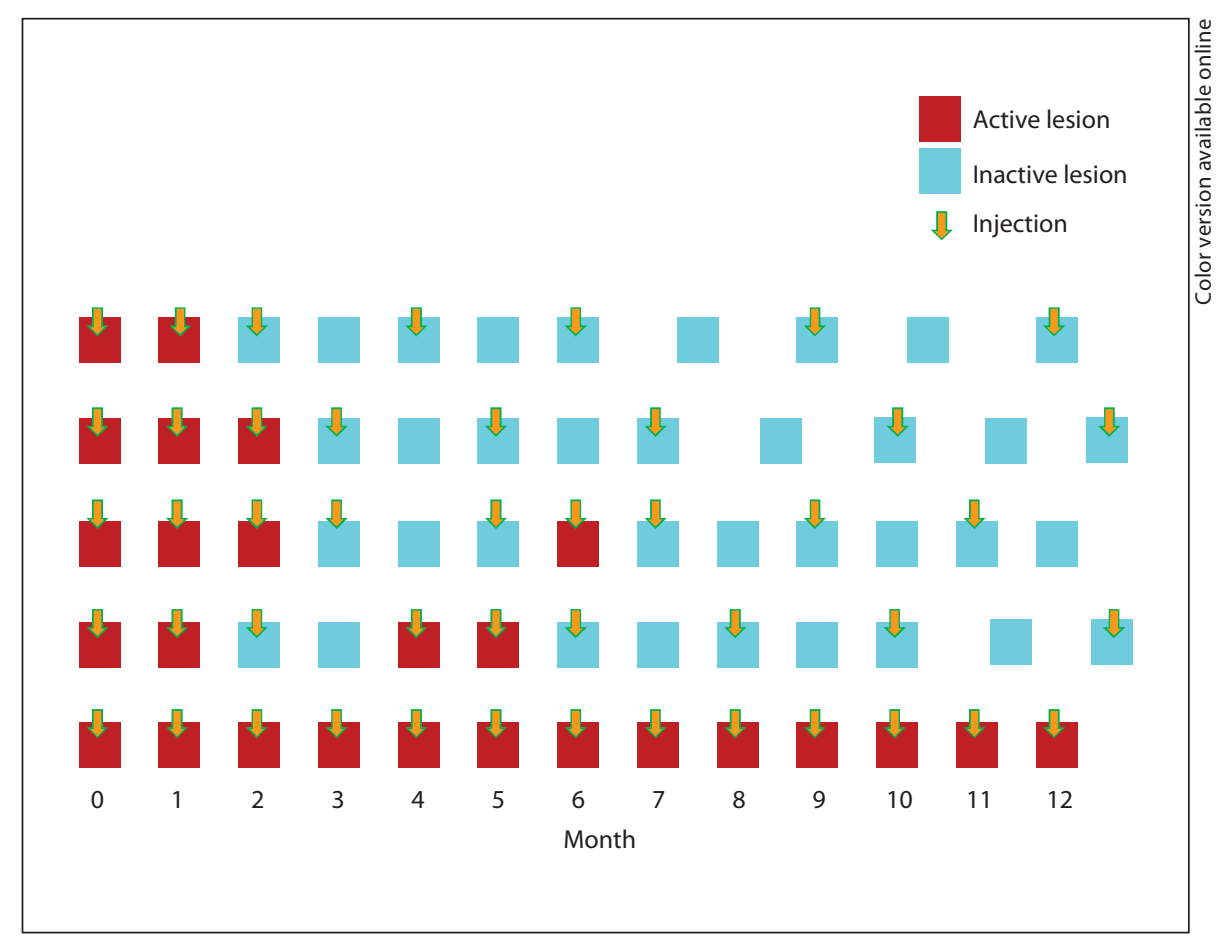

Fig. 6. FUSION regimen: examples of regimens of injections combining PRN and fixed-dose injection regimens according to lesion activity. The initiation phase is followed by a PRN regimen (according to the PrONTO/SUSTAIN criteria) with fixed-dose injections after a period of inactivity of between 1 and 4 months (depending on the time elapsed since the last injection). At the first sign of lesion activity, treatment is restarted. For example, a patient who had no activity after the initiation phase (top line) would be seen monthly and, if the patient continued without activity, he/she would be treated every 2 months for 2 cycles. The patient would then be followed up 6 weeks later, and if there was still no disease activity, treatment would start again 6 weeks later, 3 months after the last injection, and likewise successively. At the first sign of an active lesion, treatment would be administered. An attempt would be made to extend the intervals between each subsequent treatment to every 2 months following this injection. So, if a patient still had an active lesion in the third month of the initiation phase, treatment would begin at the following visit even if by then the activity had ceased. The retreatment cycle would be restarted in cases of relapse, beginning with 2 injections. To summarize, in the absence of disease activity at all visits following the initiation phase, the first maintenance injection is given a month after the third initiation injection, the second 2 are given every 2 months, and after that every 3 months. The bottom line shows an extreme case of a patient who shows continuous disease activity. The lines in the middle show different potential treatment schedules, depending on whether the patient experiences a relapse or not. tions being ideal from this perspective and alternative regimens being suboptimal; (4) when vision is lost, it is difficult to recover. The goal of maintaining visual acuity after the initiation phase by preempting active disease without monthly injections has yet to be achieved.

This paper proposes an innovative FUSION regimen that combines the PRN regimen with fixed injections after certain periods of (apparent) inactivity. The proposed FUSION regimen consists of an initiation phase followed by PRN retreatment (using the PrONTO/SUSTAIN criteria), combined with fixed injections after a period of disease inactivity of between 2 and 4 months (depending on the time elapsed since the last injection; fig. 6). For example, if a patient had no disease activity at the third injection at month 2 of the initiation phase, he/she would be seen monthly and, in the continued absence of active lesions, would be retreated twice at 2-month intervals (i.e. at months 4 and 6). The next visit would be scheduled for 6 weeks later (month 7.5), and in the absence of disease activity, treatment would restart 6 weeks later (month 9), 3 months after the last injection, to be repeated every 3 months with monitoring every 6 weeks, given the continued absence of active lesions. In general, treatment would be administered at the first visit at which the patient shows no disease activity, avoided at the next 
Fig. 7. Example of a patient treated with the FUSION regimen. An 80-year-old patient showed active choroidal neovascularization in his better eye with a vision of 20/50. Two years previously, the patient had been treated with a PRN regimen. There were positive results after 2 injections, with deactivation of the lesion and a gain of 1 ETDRS line of vision. The patient was treated monthly, and the lesion remained inactive for 6 months. The lesion suddenly became very active in the seventh month, despite having been inactive at the previous checkup. Vision decreased by 1 line. During the seventh and eighth months, the patient was treated and there was a remission of neovascular activity. From then on, apart from the PRN treatment criteria, he was administered maintenance injections to try to avoid another aggressive relapse similar to the one that had occurred in the seventh month, which might have led to an irreversible loss of vision. The patient was treated 2 months later and subsequently during months 13, 16, 20, 24 and 28 , which kept the lesion inactive and his visual acuity at 20/40.

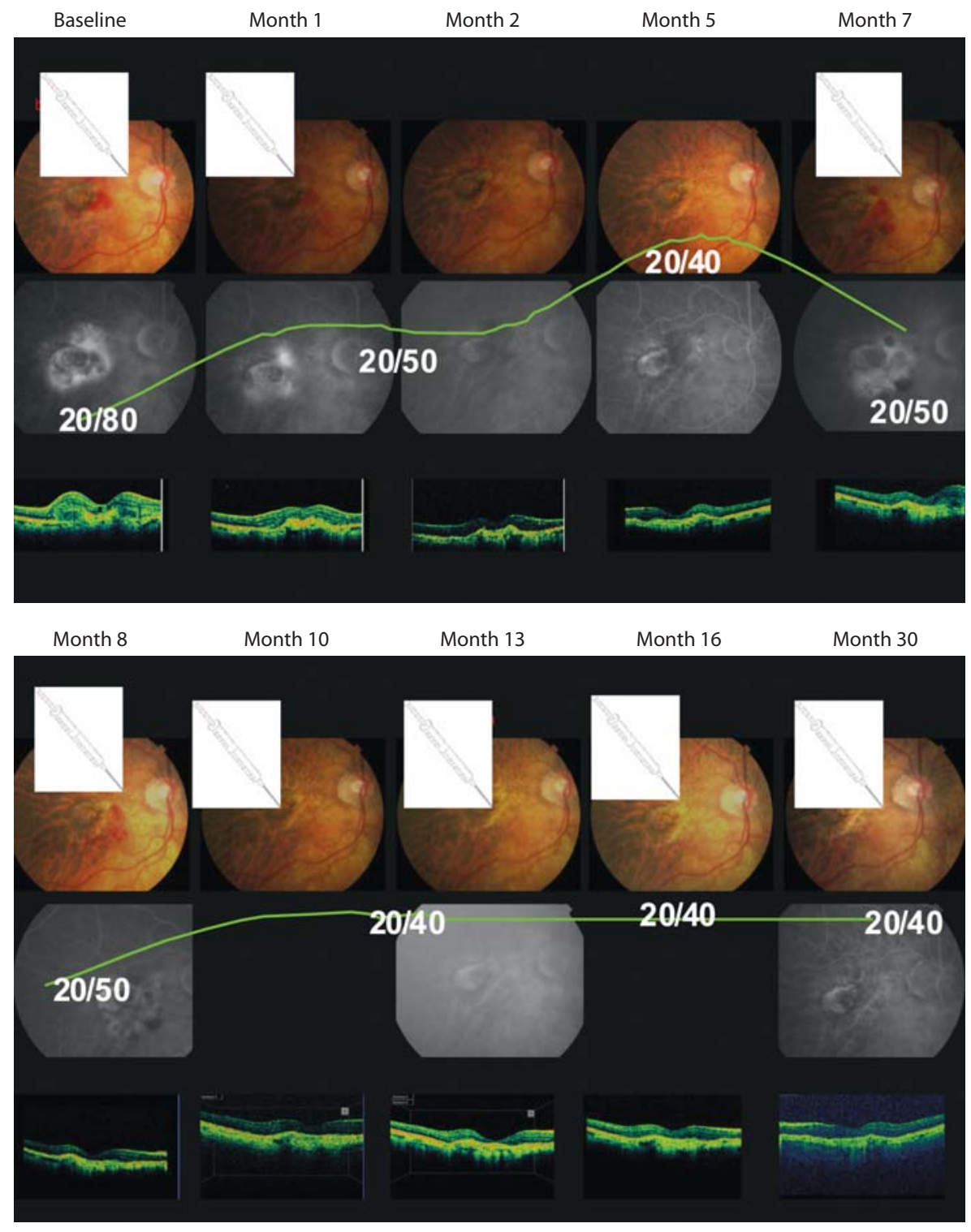

month's visit if possible and mandatory retreatment given regardless of activity status 2 months after. Thus, if a patient still had an active lesion on the third visit of the initiation phase (month 2), he/she would receive treatment at the next month's visit even if the activity was no longer evident and then miss treatment at the following month's visit (month 4). In cases of relapse, the regimen would start over again, treating until inactivity, including treatment on the first visit at which activity is no longer evident, and then following the maintenance regimen. To summarize, in the absence of disease activity, the first maintenance injection is given 2 months after- wards, for 2 cycles, and after that every 3 months, with follow-up visits without treatment in between. The first maintenance injection can be given 2 months after the initiation phase only if there is no disease activity both prior to the last initiation injection and at the next monthly visit. If the lesion remains inactive for 1 year, maintenance injections can be reduced to every 4 months in the second year.

This regimen would not significantly increase the number of injections and would preempt disease progression. Patients with disease activity would follow an injection regimen identical to the PRN regimens. Additional 
injections in the PRN regimens would only be given to patients whose disease activity has ceased. In the extreme cases of patients who show no disease activity following the initiation phase, only 3 or 4 additional injections would be given in the first year (depending on whether there are 1 or 2 intervals of 2 months), giving a total of 6-7 injections, which is slightly above the average given in the PrONTO and SUSTAIN studies [7, 9]. Those patients who showed benefit with a quarterly regimen (nearly $40 \%$ in PIER and $43 \%$ in EXCITE) would have received only 1 more injection with the FUSION regimen because the absence of signs of activity, would have precluded injections in the other follow-up visits. In the FUSION regimen, if there is no activity, patients receive 7 injections in 12 months. In PIER [3] or EXCITE [6], patients received 6 injections in 11 months.

The nonresponders from all clinical trials, including those treated with monthly injections, would not benefit on the FUSION regimen to the same extent as with a monthly regimen, but they would be likely to have better outcomes than with a PRN regimen. Since it is still not clear at baseline which patients will be nonresponders, it is not currently possible to anticipate who would receive monthly injections (since nonresponders would show choroidal neovascularization activity at follow-up visits, they would receive monthly injections until the lesion was inactive), or who would benefit from fewer injections if the FUSION regimen was followed.

The PRONTO, ANCHOR and MARINA studies showed that there was a benefit in treating for 2 years. Thus, the FUSION regimen should be followed at least for 2 years. If the lesion remains inactive for 2 years, maintenance injections could be given every 4 months. The HORIZON trial has shown that continued treatment is needed in a large proportion of patients in the third and fourth years. The less frequent dosing in years 3 and 4 was as- sociated with visual decline [12]. Therefore, a PRN regimen is likely to be insufficient even after 2 years. Thus, combining injections at fixed intervals with injections as needed when lesions relapse as proposed in the FUSION regimen appears to be an alternative to monthly injections for this extended period of treatment in years 3 and 4 .

This regimen has similarities with the proposed 'treat and extend' regimen [13], in which the intervals between treatments are extended progressively if the lesion remains inactive. The main differences between the FUSION and 'treat and extend' regimens are that in the latter, the periods between treatments are extended in a continuous linear form and there are no visits in between, which gives more opportunity for disease reactivation between treatments and thereby allows the disease the initiative. After summarizing for my patients the combined results of the past few years' studies, and explaining that the risk of vision loss from disease recurrence is always statistically much higher than vision loss from adverse effects of treatment, I suggest the FUSION regimen as a means of combining the benefits of the PRN regimen and the monthly dosing regimen (fig. 7). Vision that was previously gained or maintained during treatment can be lost when switching from the monthly to the $\mathrm{PRN}$ regimen due to undetected disease recurrence. The goal with the FUSION regimen is to avoid any such vision losses.

This proposal of a combined regimen is currently only supported by the practical review and interpretation of the results of clinical trials and their application in daily practice. A randomized clinical trial is required to compare the monthly, PRN and combined FUSION regimens to show whether the FUSION regimen is more effective than the PRN regimen and is not any less effective than the monthly regimen.

\section{References}

1 Rosenfeld PJ, Brown DM, Heier JS, Boyer DS, Kaiser PK, Chung CY, Kim RY: Ranibizumab for neovascular age-related macular degeneration. N Engl J Med 2006;355: 1419-1431.

-2 Brown DM, Kaiser PK, Michels M, Soubrane G, Heier JS, Kim RY, Sy JP, Schneider S: Ranibizumab versus verteporfin for neovascular age-related macular degeneration. $\mathrm{N}$ Engl J Med 2006;355:1432-1444.
-3 Regillo CD, Brown DM, Abraham P, Yue H, Ianchulev T, Schneider S, Shams N: Randomized, double-masked, sham-controlled trial of ranibizumab for neovascular age-related macular degeneration: PIER study year 1. Am J Ophthalmol 2008;145:239-248.

-4 Boyer DS, Heier JS, Brown DM, Francom SF, Ianchulev T, Rubio RG: A phase IIIb study to evaluate the safety of ranibizumab in subjects with neovascular age-related macular degeneration. Ophthalmology 2009;116: 1731-1739.
5 Mones J, for the EXCITE Study Group: Safety and tolerability of two dosing regimens of ranibizumab in patients with subfoveal choroidal neovascularisation secondary to agerelated macular degeneration: outcomes of the EXCITE study. 25Ith Meeting of the Club Jules Gonin, St Moritz, 2008. 
6 Eldem MB, Bartz-Schmidt KU, Schlingemann RO, Guymer R, Axer-Siegel R, on behalf of the EXCITE study group: Visual acuity responses in patients with neovascular age-related macular degeneration treated quarterly with ranibizumab in the EXCITE trial (abstract 2374). Association for Research in Vision and Ophthalmology Annual Meeting, Fort Lauderdale, 2009.

7 Fung AE, Lalwani GA, Rosenfeld PJ, Dubovy SR, Michels S, Feuer WJ, Puliafito CA, Davis JL, Flynn HW Jr, Esquiabro M: An optical coherence tomography-guided, variable dosing regimen with intravitreal ranibizumab (Lucentis) for neovascular age-related macular degeneration. Am J Ophthalmol 2007;143:566-583.
8 Holz FG, Meyer C, Eter N, on behalf of the SUSTAIN study group: Safety and efficacy of ranibizumab treatment in patients with neovascular age-related macular degeneration: 12-month results of the SUSTAIN study (abstract 3095). Association for Research in Vision and Ophthalmology Annual Meeting, Fort Lauderdale, 2009.

$\checkmark 9$ Cohen SY, Dubois L, Tadayoni R, Fajnkuchen F, Nghiem-Buffet S, Delahaye-Mazza C, Guiberteau B, Quentel G: Results of one year's treatment with ranibizumab for exudative age-related macular degeneration in a clinical setting. Am J Ophthalmol 2009;148: 409-413.

10 Dadgostar H, Ventura AA, Chung JY, Sharma S, Kaiser PK: Evaluation of injection frequency and visual acuity outcomes for ranibizumab monotherapy in exudative agerelated macular degeneration. Ophthalmology 2009;116:1740-1747.
11 Verbraak F, Schlingemann R, Mitchell P, Holz F, Inhoffen W, Weichselberger A: SUSTAIN study: evaluating visual acuity recovery after a single ranibizumab re-treatment in patients with neovascular AMD. 9th Euretina Congress, Nice, 2009.

12 Singer M, Wong P, Wang P-W, Scott L: HORIZON extension trial of ranibizumab (Lucentis $\left.^{\circledR}\right)$ for neovascular age-related macular degeneration (AMD): two-year safety and efficacy results (abstract 3093). Invest Ophthalmol Vis Sci 2009;50.

13 Spaide R: Ranibizumab according to need: a treatment for age-related macular degeneration. Am J Ophthalmol 2007;143:679-680. 